\title{
MATERNAL VITAMIN NUTRITION AND MALFORMATIONS OF THE NEURAL TUBE
}

\author{
CHRISTOPHER J. SCHORAH AND RICHARD W. SMITHELLS \\ Departments of Chemical Pathology and Paediatrics, University of Leeds, \\ Leeds LS2 9JT
}

\section{CONTENTS}

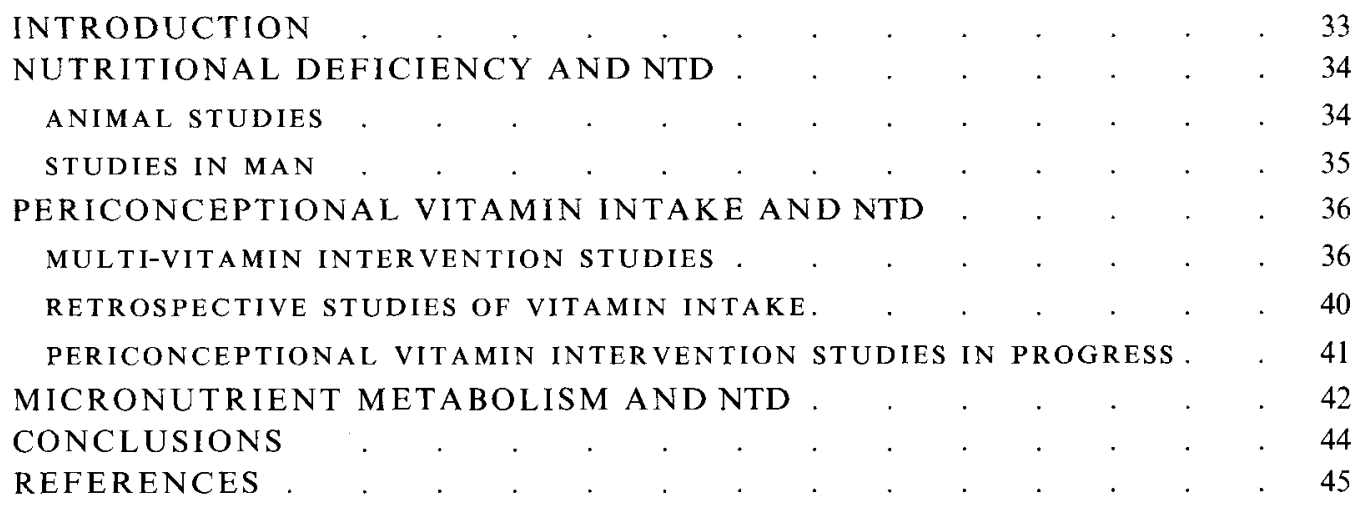

\section{INTRODUCTION}

The central nervous system (CNS), the brain and spinal cord, begins to develop very early in human embryonic life. During the $3 \mathrm{rd}$ week after conception the neural plate appears down the midline of the embryo's back, and ridges of this tissue, the neural folds, rise up each side of the midline from head to tail. Starting approximately where the brain and spinal cord will join, the apices of these folds fuse in the midline to form the neural tube. The tube is completed by closure of the top and bottom ends late in the 4th week of embryonic life.

If the head end fails to close, the cerebral hemispheres and cranial vault do not develop. This defect is called anencephalus (anencephaly) and is incompatible with life. If the tail end of the neural tube is not completed normally, the lower part of the neural plate remains exposed. This defect is myelomeningocele, a form of spina bifida, which commonly results in paralysis and loss of sensation of the lower half of the body.

Neural tube defects (NTD) are largely made up of anencephalus and spina bifida. For the purposes of the present review NTD also includes meningocele (which does not affect neural tissue) and encephalocele (which may or may not involve the brain), but not spina bifida occulta (which does not normally involve neural tissue) or isolated hydrocephalus.

Although the birth prevalence of NTD has been decreasing for some 20 years in the United Kingdom (and for longer in some other countries), they are still amongst the most common major malformations, affecting 1-5/1000 babies and a substantial number of spontaneously aborted fetuses.

A very small number of NTD have a purely genetic basis (e.g. encephalocele in Meckel's syndrome, an autosomal recessive disorder), but epidemiological and other studies indicate 
that the great majority result from an interaction between genetic and environmental factors. Genetic influences are suggested by the racial differences in NTD rates which are only partially affected by migration (Stevenson et al. 1966; Naggan \& MacMahon, 1967; Leck, 1969). For example, rates are high in the Irish, low in blacks; high in Sikhs, low in other Indian ethnic groups. Concordance for NTD is higher in monozygotic (identical) than in dizygotic twins, but in identical twins it is far below the $100 \%$ expected for a purely genetic disorder.

The relevance of non-genetic factors is indicated by the rapidity of secular changes in NTD rate (Leck, 1983), which cannot be explained on any genetic basis; the social class and geographic differences (higher rates among the less privileged, especially marked in areas of high prevalence (Leck et al. 1968; Fedrick, 1970; Wilson, 1970; Carter \& Evans, 1973; Elwood \& Nevin, 1973); the increased NTD frequency in pregnancies immediately following miscarriage (Smithells \& Chinn, 1965; Clarke et al. 1975); and the apparent preventive effect of vitamin supplementation which is here reviewed.

A variety of environmental factors which might explain the social class and geographic differences have been considered, including infection (Record, 1961), soft water (Stocks, 1970) and the consumption of blighted potatoes (Renwick, 1972). Poor nutrition also correlates broadly with the geographic and social class distribution of NTD in Britain (Smithells et al. 1976, 1977; Hurley, 1981; Rogozinski et al. 1983; Hall, 1986; Whichelow \& Erzinglioglu, 1990), although rates are relatively low in the Third World areas of protein - energy malnutrition. The association between poor nutrition and NTD has proved to be one of the most persistent features of the condition, and it applies less strikingly or not at all to other birth defects. For example, babies conceived at the height of the Dutch hunger winter towards the end of the 1939-1945 war had a higher NTD rate than those conceived before or after, but other defect rates were not increased (Stein et al. 1975).

\section{NUTRITIONAL DEFICIENCY AND NTD}

\section{ANIMAL STUDIES}

Attempting to identify the particular nutrients which may be implicated is difficult. Animal studies which allow controlled manipulation of specific nutrients may be helpful, but there are problems with this approach. There are huge inter-species differences in susceptibility to congenital malformations induced by dietary manipulations, with differences found even between different strains of a single species (Seller, 1983a). Also much animal experimental work has involved the induction of severe deficiency states which are scarcely ever applicable to man.

There are a number of reports indicating the excessive administration of vitamin $A$ or its metabolites can produce NTD (Cohlan, 1954; Marin-Padilla \& Ferm, 1965; Palludan, 1966; Seller, 1983a). In contrast, deficiencies of vitamins $E, B_{6}, B_{12}$ and pantothenic acid have been implicated in a variety of CNS malformations including NTD (LefebvresBoisselot, 1951; Cheng et al. 1960; Woodard \& Newberne, 1966; Curley et al. 1968; Davis et al. 1970). Nelson (1957) reported that anti-metabolites of folic acid administered at a critical point in embryogenesis appear to be highly teratogenic to the CNS. An apparent protective effect of folic acid has been found, its administration reducing the spontaneous NTD rate (Moffa \& White, 1983) and experimental CNS malformations induced by anti-convulsant drugs (Trotz et al. 1985; Zhu \& Zhou, 1989) and the antimalarial pyrimethamine (Horvath et al. 1988). Zinc deficiency induces CNS malformations including NTD in the rat (Hurley \& Swenerton, 1966; Rogers et al. 1985). There could be a link here with folic acid because both micronutrients are found in similar foods, are 
associated in plasma (Cherry et al. 1981) and are linked metabolically (Tamura et al. 1978, 1987; Canton et al. 1989). Combined deficiencies of $\mathrm{Zn}$ and folic acid have been found to potentiate teratogenesis in the rat (Bremert et al. 1989).

Although experimental teratogenesis in animals can only provide limited help to our understanding of the causation of NTD in man, it has pointed to a role of micronutrients, particularly vitamin A, folic acid and $\mathrm{Zn}$.

\section{STUDIES IN MAN}

In man the association found in the general population between undernutrition and the prelevance of NTD (Smithells et al. 1976, 1977; Hurley, 1977, 1981; Soltan \& Jenkins, 1982; Rogozinski et al. 1983; Al-Awadi et al. 1984; Hall, 1986; Whichelow \& Erzinglioglu, 1990) has been investigated further through studies of NTD affected pregnancies or women who have had such pregnancies and are, therefore, at increased risk of recurrence. Laurence et al. (1983) reported NTD recurrence only in infants born to women who had a poor diet, but most studies have focussed on specific micronutrients. Both vitamin C (Smithells et al. 1976; Schorah et al. 1983) and Zn deficiencies (Soltan \& Jenkins, 1982) have been implicated. Low maternal serum vitamin $B_{12}$ levels have been found early in NTD-affected pregnancies (Schorah et al. 1980), but this has not been confirmed in a larger study (Molloy et al. 1985). However, increased prevalence of NTD has been reported in women following gastric bypass surgery (Haddow et al. 1986) and these women often have low blood vitamin $\mathrm{B}_{12}$ and folic acid concentrations unless supplemented (Amaral et al. 1985). The gastric connection is strengthened by the simultaneous fall worldwide in the prevalence of both gastric cancer and NTD and the recent discovery of familial clustering of the two conditions (Janerich et al. 1990). Folic acid, vitamin $\mathbf{B}_{12}$ and ascorbic acid can all be implicated in this link because poor intakes of fresh fruit and vegetables have been associated with both conditions, and intrinsic factor and vitamin $\mathrm{C}$ are secreted in gastric juice and this secretion is impaired by chronic atrophic gastritis which seems to be a prerequisite for the development of gastric cancer (Sobala et al. 1989). The relevance of the relationship between folic acid and vitamin $B_{12}$ will be considered in more detail in the section on micronutrient metabolism and NTD; here we consider the increasing evidence for folate deficiency in the aetiology of NTD.

Evidence of disturbed folate metabolism at the end of pregnancies associated with NTD has been found by Hibbard \& Smithells (1965). However, because NTD arises during the 4th week of embryonic life it is necessary to assess potentially causal environmental factors as close to this time as possible rather than at term. In a large prospective study of vitamin nutrition in early pregnancy, Smithells et al. (1976) reported that women who were subsequently found to have had a fetus with NTD had significantly lower levels of erythrocyte (but not serum) folic acid, and leucocyte vitamin $\mathrm{C}$ than the rest of the population (Table 1). Poor folate intake in early pregnancy, but not other nutrients, has been independently associated with NTD in a case-control study (Bower \& Stanley, 1989). Very recently, folate deficiency following post-hurricane-nutritional scarcity, has been associated with a threefold rise in the incidence of NTD (Duff et al. 1991).

Indirect evidence linking folic acid metabolism with NTD comes from the observation that the folate antagonist aminopterin, when used as an abortifacient, caused malformations including those of the neural tube (Thiersch, 1952). Interference with folate metabolism could also explain the link between anti-convulsant therapy in early pregnancy and congenital malformations including NTD (Bruckner et al. 1983; Strickler et al. 1985; Lindhout \& Schmidt, 1986; Anon, 1988). Anti-convulsant drugs have been shown to lower 
Table 1. Mean maternal blood vitamin levels in the first trimester of seven neural tube defect (NTD) and seven cardiovascular system malformation (CVS) affected pregnancies compared with all pregnancies $\dagger$ (reprinted from Schorah \& Smithells (1991) with permission of Marcel Dekker Inc.)

\begin{tabular}{lcccc}
\hline \hline Pregnancy & $\begin{array}{c}\text { Serum } \\
\text { folate } \\
(\mu \mathrm{g} / 1)\end{array}$ & $\begin{array}{c}\text { Erythrocyte } \\
\text { folate } \\
(\mu \mathrm{g} / 1)\end{array}$ & $\begin{array}{c}\text { Leucocyte } \\
\text { vitamin C } \\
\left(\mu \mathrm{g} / 10^{8} \text { cells }\right)\end{array}$ & $\begin{array}{c}\text { Riboflavin } \\
\text { saturation } \\
\text { index }\end{array}$ \\
\hline All $\dagger$ & $6 \cdot 3$ & 228 & 34.5 & 1.23 \\
NTD & $4 \cdot 6$ & $136^{* * *}$ & $21.5^{*}$ & 1.30 \\
CVS & 6.1 & 239 & 30.0 & 1.22 \\
\hline
\end{tabular}

\footnotetext{
Mean values were significantly different from those of all pregnancies (one sample $t$ test): ${ }^{*} P<0 \cdot 05$; *** $P<0.001$.

$\dagger$ Approximately 1000 women who were not taking vitamin supplements.

$\$$ The higher the index the greater the deficiency.
}

blood folic acid concentrations, possibly by decreasing folate absorption (Engelsen et al. 1984; Hendel et al. 1984; Dansky et al. 1987). In an uncontrolled study Biale \& Lowenthal (1984) have reported a reduction in all malformations in the offspring of women on anticonvulsants who were given folic acid supplements through early pregnancy.

There is, therefore, ample evidence of an association between poor nutrition, particularly folate deficiency, and NTD, but it is insufficient to determine if the relationship is causal. We, therefore, undertook an intervention study to see if multi-vitamin supplements would reduce the recurrence rate of NTD in high risk women. It was hoped that this approach would better examine the role of micronutrient deficiency in the aetiology of human NTD.

\section{PERICONCEPTIONAL VITAMIN INTAKE AND NTD}

\section{MULTI-VITAMIN INTERVENTION STUDIES}

The details of these studies have been published (Smithells et al. 1980, 1981, 1983). Here only the essential features will be outlined, but the problems of interpreting the results will be considered in more detail.

Women who have previously had an infant or fetus with NTD have an approximately 10 -fold higher risk of recurrence than the general NTD rate in the population. The risk is higher if they have had more than one affected infant. To minimize the number of women required in the study, we, therefore, recruited for vitamin supplementation only those who had had at least one affected child. We felt such women would also be well motivated to comply with the study protocol. Supplements were to be started before conception, so women already known to be pregnant were excluded. Ethical approval could not be obtained for a randomized, placebo-controlled trial, so we supplemented all women recruited. The preparation used (Pregnavite Forte F; Bencard Ltd) provides approximately the recommended daily intakes of most vitamins (including folic acid but not vitamin $B_{12}$ ), iron and calcium (but not $\mathrm{Zn}$ ), for the 2nd and 3rd trimesters of pregnancy. Volunteers were asked to take the supplement for not less than $28 \mathrm{~d}$ before conception and to continue until they had missed two menstrual periods (i.e. well after the time of neural tube closure). Women who conceived less than $28 \mathrm{~d}$ after starting supplements, who started supplements after conception but before closure of the neural tube, or who missed their tablets on more than $1 \mathrm{~d}$, were classified as partially supplemented, the rest as fully supplemented. Women who proved to be pregnant when referred to the study centres (but who otherwise met the 
Table 2. Results of the multi-vitamin intervention studies

\begin{tabular}{lrrr}
\hline \hline & \multicolumn{3}{c}{ No. of infants } \\
\cline { 2 - 4 } & & \multicolumn{2}{c}{ NTD } \\
\cline { 3 - 4 } & Normal & Found & Expected* \\
\hline Fully supplemented & 426 & 3 & 20 \\
\hline Unsupplemented & 486 & 24 & 24 \\
\hline
\end{tabular}

NTD, neural tube defects.

No. of NTD found in the supplemented group was significantly different from that in the unsupplemented (Fisher's exact test): $P<0.01$.

* Assumes $4 \%$ recurrence rate after one previous NTD, $10 \%$ after two previous NTD (Seller \& Nevin, 1984).

criteria for admission to the study) were classified as unsupplemented, and their pregnancy outcomes compared with those of supplemented women.

Table 2 shows the results of the intervention study. The difference between the recurrence rates in the supplemented and unsupplemented pregnancies is striking, indicating a 7-fold reduction in rate in those who were supplemented. Since the findings in Table 2 were published the study has continued, but because an increasing proportion of mothers at recurrence risk were recruited for supplementation there is no unsupplemented group in the more recent data. Our overall experience shows fourteen NTD recurrences from 1107 fully supplemented pregnancies. This is about $25 \%$ of the expected rate estimated from contemporary population recurrence values in the regions where the trials have been undertaken, but before they made a significant impact on overall recurrence rates (Seller \& Nevin, 1984).

Two supplementation studies have been carried out using folic acid only. Laurence $e t$ al. (1983), in a randomized study, showed an apparent protective effect against NTD recurrence, but only after assuming that mothers with serum folate levels below a certain value ( $27 \%$ of the total) had been non-compliant, and combining them with the placebo group. A rather small, non-randomized study in Cuba (Vergel et al. 1990) showed NTD recurrence rates of $3.5 \%$ and $0 \%$ in unsupplemented and supplemented groups respectively, but this difference did not reach conventional levels of significance.

Because our own study was not randomized, the possibility must be considered that some unrecognized difference between the supplemented and unsupplemented mothers, which was present before they entered the study, could have accounted for the difference in recurrence rate: that is to say, the selection process led to a group of women at low risk of recurrence being chosen for supplementation (Knox, 1983; Oakley et al. 1983; Elwood, 1983; Wald \& Polani, 1984). A number of factors are known to be associated with NTD birth prevalence, and these could be associated with, and, therefore, perhaps modify, risk of recurrence, although this has not been demonstrated (Smithells \& Chinn, 1965; Carter \& Roberts, 1967; Clarke et al. 1975; Nevin et al. 1981). The most significant of these are:

1. geographic and ethnic (e.g. high rates among the Irish, low rates among negroes, including migrants to other countries);

2. secular (birth prevalence in the UK has fallen steadily since about 1972);

3. social class (e.g. higher NTD rates among poorer people);

4. outcome of previous pregnancy (NTD risk higher after miscarriage than after normal birth); 
Table 3. Effect of possible factors on risk of recurrence of neural tube defect $(N T D)$ in all mothers (supplemented and unsupplemented) in the multi-vitamin study and the differential risk between the unsupplemented and supplemented groups (risk ratio) (reprinted from Schorah \& Smithells (199I) with permission of Marcel Dekker Inc.)

\begin{tabular}{|c|c|c|}
\hline Factor & $\begin{array}{l}\text { Relative risk of } \\
\text { the factor* }\end{array}$ & $\begin{array}{l}\text { Differential risk } \\
\text { between unsupplemented } \\
\text { and supplemented group } \\
\text { due to factor (risk ratio) } \dagger\end{array}$ \\
\hline Two or more previous NTD & $2 \cdot 51$ & $1 \cdot 003$ \\
\hline Social class (IIIM, IV, V) & 0.94 & 0.992 \\
\hline Residence in Northern Ireland & $1 \cdot 35$ & $1 \cdot 040$ \\
\hline $\begin{array}{l}\text { Immediately following a } \\
\text { spontaneous abortion }\end{array}$ & $2 \cdot 18$ & $1 \cdot 032$ \\
\hline $\begin{array}{l}\text { Immediately following a } \\
\text { therapeutic abortion }\end{array}$ & $0-86$ & $1 \cdot 010$ \\
\hline $\begin{array}{l}\text { Fallow period }<1 \text { year } \\
\text { following abortion }\end{array}$ & $3 \cdot 45$ & 0.922 \\
\hline Vitamin supplements & $0 \cdot 15$ & 6.667 \\
\hline
\end{tabular}

* A comparison of pregnancy outcome between women with and without the factor who all had at least one previous NTD affected child/fetus and were, thus, at risk of recurrence. The larger the relative risk the more predisposed to NTD recurrence is a woman who has this characteristic.

$\dagger$ Values greater than unity indicate increased risk of NTD in the unsupplemented group compared with the supplemented group due to the factor, those less than one, the reverse.

5. some studies suggest that a shorter inter-pregnancy interval (fallow period) increases the risk of NTD;

6. a previous NTD increases the risk about 10-fold, and the risk increases with increasing numbers of previous NTD.

We have analysed the data from our supplementation study in relation to these potential recurrence risk factors (Wild et al. 1986) and have found no significant difference between the supplemented and unsupplemented groups (Table 3). Indeed, the only factor other than periconceptional vitamin supplementation found to affect recurrence rates significantly was two or more previous NTD, and this risk was distributed similarly in the two groups. Geographical and secular variations were not relevant because unsupplemented mothers came from the same areas over the same time-period as the supplemented. Although this analysis cannot rule out the possibility that some unknown factor with a major impact on recurrence was unevenly distributed between the two groups, this seems unlikely a priori, and such a factor is also likely to have an association with the known risk factors listed previously and, hence, be indirectly revealed by the foregoing analysis.

The possibility of some unknown bias can be looked for in an entirely different way. In two of the participating regions, Yorkshire and Northern Ireland, attempts have been made to supplement all women at risk of recurrence, and to determine the outcome of all such pregnancies, whether supplemented or not (Seller \& Nevin, 1984; Smithells et al. 1989; Nevin \& Seller, 1990). As the studies progressed, an increasing proportion of high-risk mothers were supplemented. If the lower recurrence rate seen in the supplemented group was not due to supplementation, but was because supplemented mothers were at lower risk before they entered the study, as an increasing proportion were supplemented either unsupplemented mothers would show an increasing recurrence rate or more recurrences would occur in the supplemented group and the overall recurrence rate in the two groups together would remain unchanged. This has not been the experience of either region (Table 
Table 4. Outcome of pregnancy in the multi-vitamin studies in Yorkshire and Northern Ireland divided by cohort (reprinted from Schorah \& Smithells (1991) with permission of Marcel Dekker Inc.)

\begin{tabular}{|c|c|c|c|c|c|c|}
\hline \multirow[b]{2}{*}{ Years of cohort $\uparrow \ldots$} & \multicolumn{3}{|c|}{ Northern Ireland* } & \multicolumn{3}{|c|}{ Yorkshire } \\
\hline & $1977-9$ & $1980-1$ & $1982-9$ & $1977-80$ & $1981-4$ & $1985-7$ \\
\hline Total no. of fetuses & 183 & 232 & 531 & 263 & 134 & 126 \\
\hline No. of unsupplemented $(\%)$ & $126(69)$ & $117(50)$ & $110(21)$ & $216(82)$ & $61(46)$ & $43(34)$ \\
\hline $\begin{array}{l}\text { No. of unsupplemented } \\
\text { recurrences }(\%)\end{array}$ & $6(4 \cdot 8)$ & $6(5 \cdot 1)$ & $5(4 \cdot 6)$ & $13(6 \cdot 0)$ & $3(4 \cdot 9)$ & $2(4 \cdot 7)$ \\
\hline $\begin{array}{l}\text { No. of supplemented } \\
\text { recurrences }(\%)\end{array}$ & $0(0 \cdot 0)$ & $1(0 \cdot 9)$ & $3(0 \cdot 7)$ & $1(2 \cdot 1)$ & $0(0 \cdot 0)$ & $0(0 \cdot 0)$ \\
\hline $\begin{array}{l}\text { Overall recurrence } \\
\text { rate }(\%) \S\end{array}$ & $3 \cdot 3$ & $3 \cdot 0$ & $1 \cdot 5$ & $5 \cdot 3$ & $2 \cdot 2$ & $1 \cdot 6$ \\
\hline
\end{tabular}

* From Seller \& Nevin (1984), Nevin \& Seller (1990) and Seller (unpublished results).

+ Cohort dates in Northern Ireland were determined by preparation of data for publication and in Yorkshire by change in approach to ascertainment. Recurrence rates were not calculated until the cohorts were closed.

t Includes all examined fetuses, including partially supplemented.

$\S$ Recurrence rate in Northern Ireland at the start of the study $4.2 \%$ (Seller \& Nevin, 1984).

4). Recurrence rates have remained constant in both groups, with a 7 -fold lower rate in the supplemented group. The overall recurrence rate has decreased as the proportion of women supplemented has increased, at a rate unlikely to be the result of a simple secular trend. Indeed, there is no evidence that the secular fall in NTD prevalence (Leck, 1983) has been followed by any major change in the recurrence rate, and certainly not of the order of the decrease seen in Yorkshire and Northern Ireland (Seller \& Hancock, 1985; Czeizel, 1988).

Is it possible that some feature of the study other than the vitamin supplement has been responsible for the results? Two possibilities deserve consideration. In some participating centres, women were asked to avoid oral contraceptives (OC) for at least $28 \mathrm{~d}$ before conception because of the recognized ability of $\mathrm{OC}$ to depress the plasma levels of some vitamins. However, there is no good evidence linking OC with NTD or any other malformation, even when taken in early pregnancy.

The pregnancies of supplemented mothers were planned, and this would not be true of many unsupplemented pregnancies. Might the efficiency of pregnancy planning reflect some other factor relevant to NTD recurrence? Some of the partially supplemented mothers in our study were already in the early days of pregnancy when we first met them, but had not yet reached the dead-line for neural tube closure and they were, therefore, started on supplements. NTD recurrence in this group was very low, yet their pregnancies were largely unplanned (Sheppard et al. 1989). Conversely, when the potato blight hypothesis of Renwick (1972) was tested by potato avoidance trials (Nevin \& Merrett, 1975), similar pregnancy planning was required but NTD recurrence rates were unaffected.

Finally, vitamin supplements did not have a pseudo-protective effect by inducing spontaneous abortion of affected fetuses (Creasy \& Alberman, 1976; MacHenry et al. 1979). The proportion of pregnancies ending in spontaneous abortion was comparable in the two groups (supplemented 10.7\%: unsupplemented $8.1 \%$ ), and of the forty-three spontaneously aborted fetuses it was possible to examine, only one had NTD.

In conclusion, critical analysis of the multi-vitamin intervention studies for effects of bias introduced by non-randomization of volunteers into supplemented and unsupplemented groups has found none. The most straightforward interpretation of the findings remains 
Table 5. Summary of the findings of retrospective studies of periconceptional multi-vitamin use and the prevalence of neural tube defects (NTD)

\begin{tabular}{|c|c|c|c|c|}
\hline \multirow[b]{2}{*}{ Study } & \multirow{2}{*}{$\begin{array}{c}\text { Approximate population } \\
\text { prevalence rate } / 1000 \\
\text { births } \dagger\end{array}$} & \multicolumn{3}{|c|}{ Relative risk of NTD pregnancy } \\
\hline & & $\begin{array}{l}\text { Vitamins without } \\
\text { folic acid }\end{array}$ & $\begin{array}{l}\text { Vitamins with } \\
\text { folic acid }\end{array}$ & $\begin{array}{l}\text { All } \\
\text { vitamins }\end{array}$ \\
\hline Winship et al. (1984) & $2 \cdot 0$ & 1.5 & $0 \cdot 14^{*}$ & - \\
\hline Mulinare et al. (1988) & 1.8 & - & 一 & $0.41 * *$ \\
\hline Mills et al. (1989) & $0 \cdot 9$ & - & 0.94 & 0.97 \\
\hline Milunsky et al. (1989) & $3 \cdot 5$ & 0.93 & $0.27^{* *}$ & $0 \cdot 32^{* *}$ \\
\hline
\end{tabular}

$\dagger$ Contemporaneous with study dates.

Decreased risk associated with periconceptional vitamin use was significant: ${ }^{*} P<0 \cdot 1, * * P<0 \cdot 05$.

that periconceptional multi-vitamin supplements have caused a significant decrease in the recurrence of NTD.

\section{RETROSPECTIVE STUDIES OF VITAMIN INTAKE}

The findings of the multi-vitamin trial have prompted a number of researchers to investigate retrospectively the relationship between the prevalence of NTD and periconceptional vitamin supplementation. Four case-control studies have been reported and the results are summarized in Table 5.

There are two inherent problems in such studies. Women are asked to recall their vitamin intake in early pregnancy, sometimes after a period of several years. This introduces recall bias, because apart from the difficulty of accurate recall, there is also sometimes a desire to find reasons for an adverse outcome to pregnancy which could encourage denial of vitamin use. In addition, pregnancy outcome was analysed in terms of the mothers' periconceptional vitamin use, and it is possible that women who choose to take supplements early in pregnancy are different in ways which could, independently of vitamin use, reduce their risk of NTD (analysis bias).

In the study of Winship et al. (1984), recall bias was minimized by the use of general practitioner records, but the numbers in the study were small. It is interesting to note that the evidence suggests that whilst folic acid was protective if taken in the pre-pregnancy trimester, it was less so when started during the first trimester of pregnancy, and other vitamins and Fe supplements without folic acid were not protective at any stage. This suggests the possibility of a real folic acid effect which was not due to analysis bias, as it is improbable that there would be substantial differences between women who take micronutrients containing folic acid and those who use similar preparations, but without the vitamin.

In the study of Mulinare et al. (1988) recall of self-administered vitamins was sometimes required over several years. This considerably weakens the power of the study, especially as pregnancy outcome was known, though not to the interviewer. However, recall bias was reduced by comparing vitamin use in NTD pregnancies with those where other malformations had occurred. The data were adjusted for known confounding variables which reduces analysis bias but, as the authors note, would not eliminate it. As with the study of Winship et al. (1984) the protective effect of vitamins was only found in the periconceptional period and not after the time of closure of the neural tube.

The study of Mills et al. (1989) is similar to that of Mulinare et al. (1988) but has reduced recall bias, the women being interviewed within 1 year of vitamin usage. No protective 
effect of vitamins was found. Mills et al. (1989) classified as non-takers those who started taking their vitamin supplements after conception. As another study suggests that vitamins started during early pregnancy, but before the time of neural tube closure, have a protective effect (Sheppard et al. 1989), this misclassification will tend to reduce any true difference between takers and non-takers.

Finally, in a similar study, but using women undergoing amniocentesis, a protective effect of folic acid, but not vitamins without folate, was found when the therapy was periconceptional (Milunsky et al. 1989). The protective effect was lost when folic acid supplements were started more than 6 weeks after the end of the last monthly period. This study comes closest to eliminating the problems of bias as information about supplementation use was sought before the end of second trimester of pregnancy, and at this stage pregnancy outcome was largely unknown. Because the data were adjusted for confounding factors and, as in the study of Winship et al. (1984), the effect was only seen with folate and not for vitamins without folate and then only if taken before the 6th week of pregnancy, the possibility of analysis bias producing the differences found is reduced.

Overall these studies indicate a protective effect of folic acid in early pregnancy. However, the report of Mills et al. (1989), one of the two best studies, does not support this. A possible reason for this difference could be in the prevalence of NTD in the populations selected for study. Experience in Northern Ireland, an area of high prevalence, and southeast England, (relatively low), indicates that multi-vitamin supplementation has continued to be effective in reducing NTD recurrence in Northern Ireland, but is less effective in south-east England (Seller \& Nevin, 1984; Nevin \& Seller, 1990). Table 5 shows that the prevalence rate for NTD in the retrospective study of Mills et al. (1989) is only half that of the other study areas and is close to the rate which suggests little environmental contribution to the prevalence of NTD (Janerich \& Piper, 1978). It is also relevant that in one of the studies (Mulinare et al. 1988) the protective effect of vitamin supplementation was only significant in whites, in whom the condition is known to be more prevalent than in blacks (Khoury et al. 1982). This suggestion of an association between prevalence and success of treatment has implications for the prevention of NTD using multi-vitamins and for future randomized studies of periconceptional vitamin therapy. It may also provide clues to the aetiology of the condition.

\section{PERICONCEPTIONAL VITAMIN INTERVENTION STUDIES IN PROGRESS}

Although there is now a substantial amount of evidence suggesting a role for periconceptional vitamin supplements, especially folic acid, in the prevention of NTD, difficulties in interpreting many of the studies have encouraged researchers to begin randomized trials. We know of three such studies, two in women who are at risk of recurrence (Wald \& Polani, 1984; Lenehan et al. 1988) and one study which is investigating prevention of first occurrence (Czeizel \& Fritz, 1989). Because NTD recurrences represent only a small minority of all NTD births, and because vitamin supplements have not yet been shown to prevent first occurrence, the study of Czeizel (Czeizel \& Fritz, 1989) is of particular interest. The interim results of this study are consistent with a preventive role for periconceptional vitamin supplements (Czeizel \& Fritz, 1989).

These studies are to be welcomed as they will almost certainly help to clarify the issue, but they may not resolve it completely. Since these programmes were started there has been an increase in folic acid consumption in women of child-bearing age in the United Kingdom due to fortification of certain breakfast cereals ( $\mathrm{J}$. Wild, personal communication). More directly, increased awareness in women at recurrence risk of the 
potential benefits offered by multi-vitamin therapy and the availability of multi-vitamin preparations from health food outlets may well encourage self-supplementation. Both these factors are likely to lead to an increase in folic acid supply to the fetus at the time of closure of the neural tube in women in all therapy arms of the randomized intervention studies.

We have already commented on the observation that success of periconceptional multivitamin supplementation seems to be directly associated with the prevalence of the condition. Prevalence has decreased in the United Kingdom during the last 15 years (Leck, 1983). This, combined with the increased folic acid intake in early pregnancy, may reduce the differences in recurrence rates between placebo and active-therapy groups in current intervention studies even if vitamins have a role to play in the prevention of recurrence.

\section{MICRONUTRIENT METABOLISM AND NTD}

We have already indicated that NTD probably arises from an interaction between genetic and environmental factors, in which case it should be possible to consider the role of nutrients from both genetic and environmental aspects. On theoretical grounds, both could contribute to inadequate quantities of nutrients reaching the fetus. Diet could alter the supply and genetic factors the metabolism of nutrients, leading to reduced nutrient provision to the embryo, the two interacting to affect neural tube closure. There is experimental evidence for such an interaction, especially with regard to folic acid.

Maternal folic acid deficiency alone does not always cause NTD. Some studies have found an association between CNS malformations and severe folic deficiency while others have not (Fraser \& Watt, 1964; Pritchard et al. 1970). Subjects in these studies were investigated at term when folate status may not reflect the situation in early pregnancy. However, in our study of maternal nutrition in early pregnancy, although vitamin status on average was poorer in those who had an affected pregnancy (Table 1), a number of women with the lowest vitamin levels had normal babies (Smithells et al. 1976). Conversely, periconceptional multi-vitamin supplementation as practised by us, although associated with a considerable decrease in NTD recurrence, does not always prevent it (Table 2).

These findings are consistent with a defect of folic acid metabolism which is not severe enough to induce clinical problems in the mother but, when dietary supply is limited, could affect the fetus either because of the increased requirements of pregnancy (Schorah, 1988), or because of a direct effect on transfer of vitamins to the fetus. Women who have had NTD affected pregnancies when supplemented with vitamins could have metabolic problems which are not responsive to supplementation or require supra-physiological doses of vitamins. The increased frequency of supplemented recurrences in low prevalence areas would then be accounted for by the fact that vitamin responsive women are already effectively treated by the better micronutrient nutrition present in these regions (Table 6 ; Tan et al. 1984).

Is there any evidence for the existence of minor defects of folate metabolism in man? There are some indications that metabolic differences in folate handling exist between individuals in the general population, especially in pregnancy (Schorah, 1988). Investigations of women at increased risk of NTD have shown evidence of disturbances in both folate and vitamin $\mathrm{B}_{12}$ metabolism. Abnormal $\mathrm{N}$-formiminoglutamate excretion in women at the end of an NTD pregnancy, possibly reflecting deranged folate metabolism, was identified several decades ago (Hibbard \& Smithells, 1965). More recently, such women when not pregnant have been found to have lower erythrocyte folate levels than the general population: the greater the risk of NTD, the lower the mean erythrocyte folate (Schorah et al. 1983; Yates et al. 1987). We have subsequently shown that the relatively close 
Table 6. Folic acid intake and blood levels in women in different regions of the British Isles*

(Mean values with their standard errors)

\begin{tabular}{|c|c|c|c|c|c|c|}
\hline \multirow[b]{2}{*}{ Region ${ }^{\dagger}$} & \multicolumn{2}{|c|}{$\begin{array}{c}\text { Intake } \ddagger \\
(\mu \mathrm{g} / \mathrm{d})\end{array}$} & \multicolumn{2}{|c|}{$\begin{array}{l}\text { Serum } \\
\text { folate } \$ \\
(\mu \mathrm{g} / 1)\end{array}$} & \multicolumn{2}{|c|}{$\begin{array}{c}\text { Erythrocyte } \\
\text { folate } \delta \\
(\mu \mathrm{g} / 1)\end{array}$} \\
\hline & Mean & $\mathrm{SE}$ & Mean & $\mathrm{SE}$ & Mean & $\mathrm{SE}$ \\
\hline London & 187 & $9 \cdot 6$ & 9.7 & 0.4 & 316 & 10 \\
\hline Leeds & 148 & $5 \cdot 0$ & $6 \cdot 3$ & $0 \cdot 1$ & 228 & 3 \\
\hline Republic of Ireland & 135 & $6 \cdot 0$ & $4 \cdot 7$ & $0 \cdot 3$ & 214 & 10 \\
\hline
\end{tabular}

* Data from Smithells et al. 1976; Leck, 1983; Rogozinski et al. 1983; Wickham et al. 1983.

$\uparrow$ Measurements in London and Leeds during the 1st trimester of pregnancy; in Ireland in non-pregnant women.

$\ddagger$ Estimated by weighed procedure (minimum $3 \mathrm{~d}$ ), with total folate intake in Leeds and Ireland calculated from the same database.

$\S$ Estimated by Lactobacillus casei microbiological technique.

Table 7. Incorporation of methyl groups from $\left[{ }^{14} \mathrm{C}\right]$ methyl-tetrahydrofolate $(\mathrm{MTHF})$ into trophoblast DNA in tissue culture (disintegrations/min per $10^{6}$ cells)

(Mean values with their standard errors)

\begin{tabular}{|c|c|c|c|c|c|c|c|c|c|c|c|c|}
\hline \multirow{3}{*}{$\begin{array}{l}\text { Trophoblast } \\
\text { source }\end{array}$} & \multicolumn{12}{|c|}{ Time-interval (h) after addition of $\left[{ }^{\mathbf{1 4}} \mathrm{C}\right] \mathrm{MTHF}$ to culture } \\
\hline & \multicolumn{2}{|c|}{18} & \multicolumn{2}{|l|}{36} & \multicolumn{2}{|l|}{54} & \multicolumn{2}{|c|}{72} & \multicolumn{2}{|c|}{90} & \multicolumn{2}{|c|}{108} \\
\hline & Mean & $\mathrm{SE}$ & Mean & SE & Mean & $S E$ & Mean & $\mathrm{SE}$ & Mean & $\mathrm{SE}$ & Mean & $\mathrm{SE}$ \\
\hline Control ( $n 5)$ & 27 & 9 & 109 & 28 & 127 & 13 & 187 & 23 & 213 & 17 & 222 & 19 \\
\hline $\begin{array}{l}\text { NTD-affected } \\
\text { pregnancy }(n 5)\end{array}$ & 18 & 8 & $40^{*}$ & 15 & $83^{*}$ & 32 & 151 & 27 & 215 & 32 & 232 & 31 \\
\hline
\end{tabular}

NTD, neural tube defect

* Values not significantly different from $18 \mathrm{~h}$ (paired $t$ test)

relationship between erythrocyte folate and dietary intake of the vitamin is lost in women who have had two previous NTD malformed fetuses and who are, therefore, at very high risk of recurrence ( $\mathrm{J}$. Wild, personal communication). These investigations were undertaken in non-pregnant women, but women carrying an affected fetus have consistently shown lower erythrocyte folate levels (Smithells et al. 1976), but not decreased serum concentrations (Hall, 1972, 1977; Smithells et al. 1976; Molloy et al. 1985; Scott et al. 1990). Taken together these findings suggest a metabolic disturbance primarily affecting the cellular folate pool.

We have recently been studying the folic acid metabolism of trophoblast cells grown in tissue culture. Overall uptake of radioactive labelled methyl-tetrahydrofolate and its incorporation into DNA is similar in tissue taken from normal and NTD affected pregnancies. However, the initial rate of uptake is much more rapid in trophoblasts cultured from normal than from affected pregnancies (Habibzadeh et al. 1990) (Table 7).

Finally, raised levels of vitamin $B_{12}$-binding proteins (transcobalamins I and II) have been reported in the amniotic fluid of pregnant women who have had previous NTD affected pregnancies (Magnus et al. 1986; Gardiki-Kouidou \& Seller, 1988). Disturbance 
of vitamin $B_{12}$ metabolism could affect folic acid distribution because of the metabolic inter-relationships of the two vitamins (Scott \& Weir, 1981). All these studies suggest that the cell uptake of folic acid is affected in women at high risk for NTD or their fetuses. The studies on periconceptional vitamin supplementation support the concept that such metabolic disadvantages can be overcome by appropriate vitamin therapy in the majority of women with these lesions. The evidence is sufficient to support detailed investigation of folic acid metabolism in women at increased risk of NTD. The identification of metabolic abnormalities would make screening for such defects feasible. Vitamin prophylaxis could then be confined to this selected population as they reach child-bearing age.

\section{CONCLUSIONS}

We suggest that the accumulated evidence, particularly from the multi-vitamin intervention studies and the prospective studies published more recently in the USA, indicate that periconceptional multi-vitamin supplements, and folic acid in particular, can reduce the recurrence rate, and probably the prevalence, of NTD. We, therefore, recommend that the supplementation of women at risk of NTD recurrence should now become routine. This approach has most to offer in areas of high prevalence.

Although evidence suggests that folic acid deficiency is most closely linked to the causation of NTD, and this is biologically plausible because it is essential for DNA synthesis and cell division (Rolschau et al. 1979; Seller, 1983 b), we would at the present time, suggest supplementation with multi-vitamins at the recommended daily allowance for pregnancy, because this is the only therapy for which there is substantial evidence of safety and efficacy. In addition, good nutrition should always be encouraged, especially in women of child-bearing age, but this may be difficult to attain, especially among the disadvantaged in society, in whom NTD prevalence is highest.

In making such a recommendation we have considered the possibility of harmful effects of such treatment. There is evidence that vitamin $\mathbf{A}$ in doses greater than tenfold those provided by the supplement used in the vitamin intervention trials can be harmful in early pregnancy (Bernhardt \& Dorsey, 1974; Stange et al. 1978; Rosa, 1983). However, there are no reports of vitamins taken at the levels recommended for pregnancy causing harm. In over 1000 supplemented pregnancies in the intervention studies we have observed no excess of malformations and no disturbances of post-natal growth and development. However, trialists must continue to look for evidence of harm. This would be particularly relevant if treatment were to be extended to the general population among whom a much smaller proportion would stand to benefit from it.

It is important to begin vitamin treatment before the closure of the neural tube. Our overall experience suggests that, while $28 \mathrm{~d}$ of preconceptional supplementation achieves satisfactory blood vitamin levels (Schorah et al. 1983), such early supplementation may not be essential (Sheppard et al. 1989). Starting supplements before the 20th day after conception may prove to be satisfactory, but we would advise caution here. We have seen a high NTD rate among a small number of women in whom supplements were started at times later calculated to be $27-41 \mathrm{~d}$ post-conception, that is after the usual time of closure of the neural tube (Sheppard et al. 1989). We are aware of possible parallels here with the effect of vitamin A administration in the curly tail mouse, where the precise time of the administration determines whether the prevalence of NTD is reduced or increased (Seller, $1983 a$ ). The recent findings of metabolic differences in handling of folate and vitamin $B_{12}$ by women at increased risk of NTD should stimulate further research in this area. This could not only help to elucidate the causal mechanism, but could lead to the development 
of a screening test which would identify the metabolic lesion associated with liability to NTD and prevent unnecessary supplementation of very large numbers of women.

The authors would like to acknowledge contributions to these studies of the following colleagues: Dr Sheila Sheppard, Mrs Jenny Wild, Dr Mary Seller, Professor Norman Nevin, Professor Rodney Harris, Dr Andrew Read, Dr David Fielding and the late Dr Stanley Walker. They also wish to record their gratitude to the following for research support: Action Research for the Crippled Child, Children's Research Fund, Department of Health, Beecham Pharmaceuticals Plc., Roche Products Plc.

During the preparation of this review, clarification of the role of vitamins in the prevention of NTD has come with the publication of the results of the UK Medical Research Council's study (MRC Vitamin Study Research Group, 1991). In a randomised study, a significant $(72 \%)$ reduction in NTD recurrence was achieved by periconceptional supplementation with folic acid, $4 \mathrm{mg} / \mathrm{d}$, but not with other vitamins. These findings support the data presented in this review and underline many of the conclusions.

The smaller reduction in recurrence rate achieved in the MRC study (3-fold) compared with our own studies (7-fold) (Smithells et al. 1983) was predicted and the possible reasons for the difference considered (p. 41).

The choice between the folic acid doses used by the MRC ( $4 \mathrm{mg})$ and by our group $(0.36 \mathrm{mg})$ is not straightforward. For women with a family history of NTD, the higher dose may be appropriate (in practice $5 \mathrm{mg} / \mathrm{d}$ as $4 \mathrm{mg}$ tablets are not commercially available), but this will only prevent NTD recurrences. For the prevention of first occurrences, a lower dose is more logical because it can be widely administered by fortification of staple foods, and because the risk of side-effects (e.g. nausea) with higher doses is avoided. However, it is possible that, because of the supporting role of a number of micronutrients in the metabolism of folic acid (Schorah, 1988), the lower dose may not be as effective without the accompanying vitamins. The ongoing study of Lenehan et al. (1988) should resolve this issue as it includes a comparison of low dose folate with and without other vitamins.

Whether the causation of NTD includes an inborn error of metabolism which can be largely prevented by folic acid, or whether NTD is a newly-recognised symptom of dietary folate deficiency, remains to be determined. If the former, it is unusually common for an inherited metabolic defect: if the latter, dietary deficiency can occur with folate intakes achieved by most women on a typical UK diet.

Either way, we seem to have something new to medical science. This makes the continuing study of the precise role of folic acid in NTD important, not only for the reasons indicated in the conclusions to this review, but also because this may not be the only condition which can be modified by micronutrient intakes at the upper end of the usual range.

\section{REFERENCES}

Al-Awadi, S. A., Farag, T. I., Teebi, A. S., Naguib, K. K. \& El-Khalifa, M. Y. (1984). Anencephaly: disappearing in Kuwait? Lancet ii, 701-702.

Amaral, J. F., Thompson, W. R., Caldwell, M. D., Martin, H. F. \& Randall, H. T. (1985). Prospective haematologic evaluation of gastric exclusion surgery for morbid obesity. Annals of Surgery 201, $186-193$.

Anon (1988). Valproate spina bifida and birth defect registries. Lancet ii, 1404-1405.

Bernhardt, I. B. \& Dorsey, D. J. (1974). Hypervitaminosis A and congenital renal anomalies in a human infant. Obstetrics and Gynecology 43, 750-755.

Biale, Y. \& Lewenthal, H. (1984). Effect of folic acid supplementation on congenital malformations due to anticonvulsive drugs. European Journal of Obstetrics, Gynecology and Reproductive Biology 18, 211-216.

Bower, C. \& Stanley, F. J. (1989). Dietary folate as a risk factor for neural tube defects: evidence from a casecontrol study in Western Australia. Medical Journal of Australia 150, 613-619.

Bremert, J. C., Dreosti, I. E. \& Tulsi, R. S. (1989). Teratogenic interaction of folic acid and zinc deficiencies in the rat. Nutrition Reports International 39, 383-390. 
Bruckner, A., Lee, Y. J., O'Shea, K. S. \& Henneberry, R. C. (1983). Teratogenic effects of valproic acid and diphenylhydantoin on mouse embryos in culture. Teratology 27, 2942.

Canton, M. C., Cotter, B. M., Cremin, F. M. \& Morrissey, P. A. (1989). The effect of dietary zinc deficiency on pancreatic $\gamma$-glutamyl hydrolase activity and on absorption of pteroylpolyglutamate in rats. British Journal of Nutrition 62, 185-193.

Carter, C. O. \& Evans, K. (1973). Spina bifida and anencephalus in Greater London Journal of Medical Genetics 10, 209-234.

Carter, C. O. \& Roberts, J. A. F. (1967). The risk of recurrence after two children with central nervous system malformations. Lancet i, 306-308.

Cheng, D. W., Bairnson, T. A., Rao, A. N. \& Subbammal, S. (1960). Effects of variations of rations on the incidence of teratogeny in vitamin E deficient rats. Journal of Nutrition 71, 54-60.

Cherry, F. F., Bennett, E. A., Bazzano, G. S., Johnson, L. K., Fosmire, G. J. \& Batson, H. K. (1981). Plasma zinc in hypertension/toxemia and other reproductive variables in adolescent pregnancy. American Journal of Clinical Nutrition 34, 2367-2375.

Clarke, C., Hobson, D., McKendrick, O. M., Rogers, S. C. \& Sheppard, P. M. (1975). Spina bifida and anencephaly: miscarriage as possible cause. British Medical Journal iv, 743-746.

Cohlan, S. Q. (1954). Congenital anomalies in the rat produced by excessive intake of vitamin A during pregnancy. Pediatrics 13, 556-567.

Creasy, M. R. \& Alberman, E. D. (1976). Congenital malformations of the central nervous system in spontaneous abortions. Journal of Medical Genetics 13, 9-16.

Curley, F. J., Ingalls, T. H. \& Zappasodi, P. (1968). 6-aminonicotinamide induced skeletal malformations in mice. Archives of Environmental Health 16, 309-315.

Czeizel, A. (1988). Neural tube defects. Journal of the American Medical Association 259, 3562.

Czeizel, A. \& Fritz, G. (1989). Trial to prevent first occurrence of neural tube defects by periconceptional multivitamin supplementation. Journal of the American Medical Association 262, 1634.

Dansky, L. V., Andermann, E., Rosenblatt, D., Sherwin, A. L. \& Andermann, F. (1987). Anticonvulsants, folate levels and pregnancy outcome: a prospective study. Annals of Neurology 21, 176-182.

Davis, S. D., Nelson, T. \& Shepard, T. H. (1970). Teratogenicity of vitamin $B_{6}$ deficiency: omphalocele, skeletal and neural defects and splenic hypoplasia. Science 169, 1329-1330.

Duff, E. M. W., Cooper, E. S., Danbury, C. M., Johnson, B. E., Serjeant, G. R. (1991). Neural tube defects in hurricane aftermath. Lancet 337, 120-121.

Elwood, J. M. (1983). Can vitamins prevent neural tube defects? Canadian Medical Association Journal 129, $1088-1092$.

Elwood, J. H. \& Nevin, N. C. (1973). Factors associated with anencephalus and spina bifida in Belfast. British Journal of Preventive and Social Medicine 27, 73-80.

Engelsen, B., Strandjord, R., Gjerde, I. O., Markestad, T., Ulstein, M. \& Evjen, O. K. (1984). Folate concentrations in pregnancies in women on antiepileptic drug therapy. Acta Neurologica Scandinavica 69 Suppl. 98, 83-84.

Fedrick, J. (1970). Anencephalus: variation with maternal age, parity, social class and region in England, Wales and Scotland. Annals of Human Genetics 34, 31-38.

Fraser, J. L. \& Watt, H. J. (1964). Megaloblastic anaemia in pregnancy and the puerperium. American Journal of Obstetrics and Gynecology 89, 532-534.

Gardiki-Kouidou, P. \& Seller, M. J. (1988). Amniotic fluid folate, vitamin B $_{12}$ and transcobalamins in neural tube defect. Clinical Genetics 33, 441-448.

Habibzadeh, N., Smithells, R. W. \& Schorah, C. J. (1990). Folic acid metabolism in placental cells associated with neural tube defects. In Chemistry and Biology of Pteridines, pp. 1257-1261 [H. C. Curtius, S. Ghisla and N. Blau, editors]. Berlin: Walter de Gruyter.

Haddow, J. E., Hill, L. E., Kloza, E. M. \& Thanhauser, D. (1986). Neural tube defects after gastric bypass. Lancet i, 1330 .

Hall, J. G. (1986). Neural tube defect among the Sikh population of British Columbia. Proceedings of the Greenwood Genetic Centre 5, 129-131.

Hall, M. H. (1972). Folic acid deficiency and congenital malformation. Journal of Obstetrics and Gynecology of the British Commonwealth 79, 159-161.

Hall, M. H. (1977). Folates and the foetus. Lancet i, 648-649.

Hendel, J., Dam, M., Gram, L., Winkel, P. \& Jorgensen, I. (1984). The effects of carbamazepine and valproate on folate metabolism in man. Acta Neurologica Scandinavica 69, 226-231.

Hibbard, E. D. \& Smithells, R. W. (1965). Folic acid metabolism and human embryopathy. Lancet i, 1254.

Horvath, C., Compagnon, A. \& Petter, C. (1988). Teratogenic effect of pyrimethamine in the rat: in vivo prevention by calcium folinate. Comptes Rendus de la Société de Biologie 182, 158-166.

Hurley, L. S. (1977). Nutritional deficiencies and excesses. In Handbook of Terataology, vol. 1, pp. 261-308 [J. G. Wilson and F. C. Fraser, editors]. New York: Plenum Press.

Hurley, L. S. (1981). Zinc deficiency and CNS malformations in humans. American Journal of Clinical Nutrition 34, 2864-2865.

Hurley, L. S. \& Swenerton, H. (1966). Congenital malformations resulting from zinc deficiency in rats Proceedings of the Society for Experimental Biology and Medicine 123, 692-697. 
Janerich, D. T., Mayne, S. T., Thompson, W. D., Stark, A. D., Fitzgerald, E. F. \& Jacobson, H. I. (1990). Familial clustering of neural tube defects and gastric cancer. International Journal of Epidemiology 19, 516-521.

Janerich, D. T. \& Piper, J. (1978). Shifting genetic patterns in anencephaly and spina bifida. Journal of Medical Genetics 15, 101-105.

Khoury, M. J., Erickson, J. D. \& James, L. M. (1982), Etiologic heterogeneity of neural tube defects: clues from epidemiology. American Journal of Epidemiology 115, 538-548.

Knox, E. G. (1983). Vitamin supplementation and neural tube defects. Lancet ii, 39.

Laurence, K. M., Campbell, H. \& James, N. E. (1983). The role of improvement in the maternal diet and preconceptional folic acid supplementation in the prevention of neural tube defects. In Prevention of Spina Bifida and Other Neural Tube Defects, pp. 85-125 [J. Dobbing, editor]. London: Academic Press.

Leck, I. (1969). Ethnic differences in the incidence of malformations following migration. British Journal of Preventive and Social Medicine 23, 166-173.

Leck, I. (1983). Epidemiological clues to the causation of neural tube defects. In Prevention of Spina Bifida and Other Neural Tube Defects, pp. 155-218 [J. Dobbing, editor]. London: Academic Press.

Leck, I., Record, R. G., McKeown, T. \& Edwards, J. H. (1968). The incidence of malformation in Birmingham 1950-59. Teratology 1, 263-280.

Lefebvres-Boisselot, J. (1951). Rôle tératogène de la déficience en acid pantothénique chez le rat (A teratogenic role for pantothenic acid deficiency in the rat). Annales de Médecine 52, 225-298.

Lenehan, P., MacDonald, D. \& Kirke, P. (1988). Neural tube defects and vitamin prophylaxis. In Vitamins and Minerals in Pregnancy and Lactation. Nestle Nutrition Workshop Series no. 16, pp. 177 [H. Berger, editor]. New York: Raven Press.

Lindhout, D. \& Schmidt, D. (1986). In utero exposure to valproate and neural tube defects. Lancet i, $1392-1393$.

MacHenry, J. C. R. M., Nevin, N. C. \& Merrett, J. D. (1979). Comparison of central nervous system malformations in spontaneous abortions in Northern Ireland and South East England. British Medical Journal 1, 1395-1397.

Magnus, P., Magnus, E. M. \& Berg, K. (1986). Increased levels of apotranscobalamins I and II in amniotic fluid from pregnant women with previous NTD offspring. Clinical Genetics 30, 167-172.

Marin-Padilla, M. \& Ferm, V. H. (1965). Somite necrosis and developmental malformations induced by vitamin $\mathrm{A}$ in the golden hamster. Journal of Embryology and Experimental Morphology 13, 1-8.

Mills, J. L., Rhoads, G. C., Simpson, J. L., Cunningham, G. C., Conley, M. R., Lassman, M. R., Walden, M. E., Depp, O. R. \& Hoffman, H. J. (1989). The absence of a relation between periconceptional use of vitamins and neural-tube defects. New England Journal of Medicine 321, 430-435.

Milunsky, A., Jick, H., Jick, S. S., Bruell, C. L., MacLaughlin, D. S., Rothman, K. J. \& Willett, W. (1989). Multivitamin/folic acid supplementation in early pregnancy reduces the prevalence of neural tube defects. Journal of the American Medical Association 262, 2847-2852.

Moffa, A. M. \& White, J. A. (1983). The effect of periconceptional supplementation of folic acid on the incidence of open neural tube defects in golden hamster embryos. Teratology 27, 64A.

Molloy, A. M., Kirke, P., Hillary, I., Weir, D. G. \& Scott, J. M. (1985). Maternal serum folate and vitamin $B_{12}$ concentrations in pregnancies associated with neural tube defects. Archives of Disease in Childhood 60, 660-665.

MRC Vitamin Study Research Group (1991). Prevention of neural tube defects: results of the MRC vitamin study, Lancet, 338, 131-137.

Mulinare, J., Cordero, J. F., Erickson, J. D. \& Berry, R. J. (1988). Periconceptional use of multivitamins and the occurrence of neural tube defect. Journal of the American Medical Association 260, 3141-3145.

Naggan, L. \& MacMahon, B. (1967). Ethnic differences in the prevalence of anencephaly and spina bifida in Boston Massachusetts. New England Joumal of Medicine 227, 1119-1123.

Nelson, M. M. (1957). Production of congenital anomalies in mammals by maternal dietary deficiencies. Pediatrics 19, 764-776.

Nevin, N. C., Johnston, W. P. \& Merrett, J. D. (1981). Influence of social class on the risk of recurrence of anencephalus and spina bifida. Developmental Medicine and Child Neurology 23, 155-159.

Nevin, N. C. \& Merrett, J. D. (1975). Potato avoidance during pregnancy in women with a previous infant with either anencephaly and/or spina bifida. British Journal of Preventive and Social Medicine 29, 111 115.

Nevin, N. C. \& Seller, M. J. (1990). Prevention of neural-tube-defect recurrences. Lancet 335, 178-179.

Oakley, G. P., Adams, M. J. \& James, L. M. (1983). Vitamins and neural tube defects. Lancet ii, 798-799.

Palludan, B. (1966). Swine in teratological studies. In Swine in Biomedical Research, pp. 51-78 [L. K. Bustad and R. O. McClella, editors]. Seattle: Frayn Printing Co.

Pritchard, J. A., Scott, D. E., Whalley, P. J. \& Haling, R. F. (1970). Infants of mothers with megaloblastic anaemia due to folate deficiency. Journal of the American Medical Association 211, 1982-1984.

Record, R. G. (196I). Anencephalus in Scotland. British Journal of Preventive and Social Medicine 15, 93-105.

Renwick, J. H. (1972). Hypothesis: anencephaly and spina bifida are usually preventable by avoidence of a specific but unidentified substance present in certain potato tubers. British Journal of Preventive and Social Medicine 26, $67-72$.

Rogers, J. M., Keen, C. L. \& Hurley, L. S. (1985). Zinc deficiency in pregnant Long-Evans hooded rats: teratogenicity and tissue trace elements. Teratology 31, 89-100.

Rogozinski, H., Ankers, C., Lennon, D., Wild, J., Schorah, C., Sheppard, S. \& Smithells, R. W. (1983). Folate nutrition in early pregnancy. Human Nutrition: Applied Nutrition 37 A, 357-364. 
Rolschau, J., Date, J. \& Kristoffersen, K. (1979). Folic acid supplements and intrauterine growth. Acta Obstetricia et Gynecologica Scandinavica 58, 343-346.

Rosa, F. W. (1983). Teratogenicity of isotretinoin. Lancet ii, 513.

Schorah, C. J. (1988). Importance of adequate folate nutrition on embryonic and early fetal development. In Vitamins and Minerals in Pregnancy and Lactation. Nestle Nutrition Workshop Series no. 16, pp. 167-176 [H. Berger, editor]. New York: Raven Press.

Schorah, C. J. \& Smithells, R. W. (1991). A possible role for periconceptional multivitamin supplementation in the prevention of the recurrence of neural tube defects. In Micronutrients in Health and the Prevention of Disease [A. Bendich and C. E. Butterworth, editors]. New York: Marcel Dekker Inc.

Schorah, C. J., Smithells, R. W. \& Scott, J. (1980). Vitamin B , $_{12}$ and anencephaly. Lancet i, 880.

Schorah, C. J., Wild, J., Hartley, R., Sheppard, S. \& Smithells, R. W. (1983). The effect of periconceptional supplementation on blood vitamin concentrations in women at recurrence risk for neural tube defect. British Journal of Nutrition 49, 203-211.

Scott, J. M., Kirke, P. N. \& Weir, D. G. (1990). The role of nutrition in neural tube defects. Annual Review of Nutrition 10, 277-295.

Scott, J. M. \& Weir, D. G. (1981). The methyl folate trap. Lancet ii, 337-340.

Seller, M. J. (1983a). Maternal nutritional factors and neural tube defects in experimental animals. In Prevention of Spina Bifida and Other Neural Tube Defects, pp. 1-14. [J. Dobbing, editor]. London: Academic Press.

Seller, M. J. (1983b). The cause of neural tube defects: some experiments and a hypothesis. Journal of Medical Genetics 20, 164-168.

Seller, M. J. \& Hancock, P. C. (1985). Is recurrence rate of neural tube defects declining? Lancet i, 175.

Seller, M. J. \& Nevin, N. C. (1984). Periconceptional vitamin supplementation and prevention of neural tube defects in South East England and Northern Ireland. Journal of Medical Genetics 21, 325-330.

Sheppard, S., Nevin, N. C., Seller, M. J., Wild,. J., Smithells, R. W., Reed, A. P., Harris, R., Fielding, D. W. \& Schorah, C. J. (1989). Neural tube defect recurrence after 'partial' vitamin supplementation. Journal of Medical Genetics 26, 326-329.

Smithells, R. W., Ankers, C., Carver, M. E., Lennon, D., Schorah, C. J. \& Sheppard, S. (1977). Maternal nutrition in early pregnancy. British Journal of Nutrition 38, 497-506.

Smithells, R. W. \& Chinn, E. R. (1965). Spina bifida in Liverpool. Developmental Medicine and Child Neurology 7, 258-268.

Smithells, R. W., Nevin, N. C., Seller, M. J., Sheppard, S., Harris, R., Read, A. P., Fielding, D. W., Walker, S., Schorah, C. J. \& Wild, I. (1983). Further experience of vitamin supplementation for prevention of neural tube defect recurrences. Lancet i, $1027-1031$.

Smithells, R. W., Sheppard, S. \& Schorah, C. J. (1976). Vitamin deficiencies and neural tube defects. Archives of Disease in Childhood 51, 944-950.

Smithells, R. W., Sheppard, S., Schorah, C. J., Seller, M. J., Nevin, N. C., Harris, R., Read, A. P. \& Fielding, D. W. (1980). Possible prevention of neural tube defects by periconceptional vitamin supplementation. Lancet i, 339-340.

Smithells, R. W., Sheppard, S., Schorah, C. J., Seller, M. J., Nevin, N. C., Harris, R., Read, A. P. \& Fielding, D.W. (1981). Apparent prevention of neural tube defects by periconceptional vitamin supplementation. Archives of Disease in Childhood 56, 911-918.

Smithells, R. W., Sheppard, S., Wild, J. \& Schorah, C. J. (1989). Prevention of neural tube defect recurrences in Yorkshire: final report. Lancet ii, 498-499.

Sobala, G. M., Schorah, C. J., Sanderson, M., Dixon, M. F., Tompkins, D. S., Godwin, P. \& Axon, A. T. R. (1989). Ascorbic acid in the human stomach. Gastroenterology 97, 357-363.

Soltan, M. H. \& Jenkins, D. M. (1982). Maternal and fetal plasma zinc concentrations and fetal abnormality. British Journal of Obstetrics and Gynaecology 89, 56-60.

Stange, L., Carlstrom, K. \& Eriksson, M. (1978). Hypervitaminosis A in early human pregnancy and malformation of the central nervous system. Acta Obstetricia et Gynecologica Scandianayica 57, $289-291$.

Stein, Z., Susser, M., Gerhart, S. \& Marolla, F. (1975). Famine and Human Development. The Dutch Hunger Winter of 1944-45. London: Oxford University Press.

Stevenson, A. C., Johnston, H. A., Stewart, M. I. P. \& Golding, D. R. (1966). Congenital malformations - a report of a study of series of consecutive births in 24 centres. Bulletin of the WHO 34, Suppl. 1-125.

Stocks, P. (1970). Incidence of congenital malformations in the regions of England and Wales. British Journal of Preventive and Social Medicine 24, 67-72.

Strickler, S. M., Dansky, L. V., Miller, M. A., Seni, M. H., Andermann, E. \& Spielberg, S. P. (1985). Genetic predisposition to phenytoin induced birth defects. Lancet ii, 746-749.

Tamura, T., Kaiser, L. L., Watson, J. E., Halsted, C. H., Hurley, L. S. \& Stokstad, E. L. R. (1987). Increased methionine synthetase activity in zinc deficient rat liver. Archives of Biochemistry and Biophysics 256, 311-316.

Tamura, T., Shane, B., Baer, M. T., King, J. C., Margen, S. \& Stokstad, E. L. R. (1978). Absorption of mono and polyglutamyl folates in zinc depleted man. American Journal of Clinical Nutrition 31, 1984-1987.

Tan, S. P., Wenlock, R. W. \& Buss, D. H. (1984). Folic acid content of the diet in various types of British household. Human Nutrition: Applied Nutrition 38 A, 17-22.

Thiersch, J. B. (1952). Therapeutic abortions with folic acid antagonist, 4 amino pteroylglutamic acid administered by the oral route. American Journal of Obstetrics and Gynecology 63, 1298-1304. 
Trotz, M., Gansau, C. H. \& Nau, H. (1985). Effect of folic acid deficient diet and folinic acid treatment on the embryo toxicity of valproic acid in the mouse. Teratology 32, 35A.

Vergel, R. G., Sanchez, L. R., Heredero, B. L., Rodriguez, P. L. \& Martinez, A. J. (1990). Primary prevention of neural tube defects with folic acid supplementation: Cuban experience. Prenatal Diagnosis 10, $149-152$.

Wald, N. J. \& Polani, P. E. (1984). Neural tube defects and vitamins: the need for a randomised clinical trial. British Journal of Obstetrics \& Gynaecology 91, 516-523.

Whichelow, M. J. \& Erzinglioglu, S. W. (1990). Is there a north/south divide? Regional variations in the diet of British adults. Proceedings of the Nutrition Society 49, 76A.

Wickham, C., O’Broin, S. \& Kevany, J. (1983). Seasonal variation in folate nutritional status. Irish Journal of Medical Science 152, 295-299.

Wild, J., Read, A. P., Sheppard, S., Seller, M. J., Smithells, R. W., Nevin, N. C., Schorah, C. J., Fielding, D. W., Walker, S. \& Harris, R. (1986). Recurrent neural tube defects, risk factors and vitamins. Archives of Disease in Childhood 61, 440-444.

Wilson, T. S. (1970). A study of congenital malformations of the central nervous system among Glasgow births. $1964-68$. Health Bulletin 28, 32-38.

Winship, K. A., Cahal, D. A., Weber, J. C. P. \& Griffin, J. P. (1984). Maternal drug histories and central nervous system anomalies. Archives of Disease in Childhood 59, 1052-1060.

Woodard, J. C. \& Newberne, P. M. (1966). Relation of vitamin $\mathbf{B}_{12}$ and one carbon metabolism to hydrocephalus in the rat. Journal of Nutrition 88, 375-381.

Yates, J. R. W., Ferguson-Smith, M. A., Shenkin, A., Guzman-Rodriguez, R., White, M. \& Clark, B. J. (1987). Is disordered folate metabolism the basis for the genetic predisposition to neural tube defects? Clinical Genefics 31, $279-287$

Zhu, M. X. \& Zhou, S. S. (1989). Reduction of teratogenic effects of phenytoin by folic acid and a mixture of folic acid, vitamins and amino acids. A preliminary trial. Epilepsia 30, 246-251. 